\title{
Photodynamic inactivation of planktonic Staphylococcus aureus by sodium magnesium chlorophyllin and its effect on the storage quality of lettuce
}

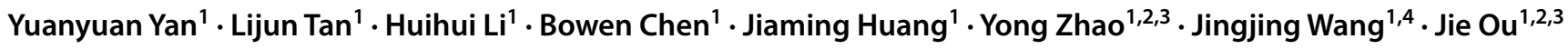

Received: 24 January 2021 / Accepted: 17 May 2021 / Published online: 28 May 2021

(c) The Author(s), under exclusive licence to European Photochemistry Association, European Society for Photobiology 2021

\begin{abstract}
Photodynamic inactivation (PDI) is a fast and effective non-heat sterilization technology. This study established an efficient blue light-emitting diode (LED) PDI with the photosensitizer sodium magnesium chlorophyllin (SMC) to eradicate Staphylococcus aureus in food. The antibacterial mechanisms were determined by evaluating DNA integrity, protein changes, morphological alteration, and the potency of PDI to eradicate $S$. aureus on lettuce was evaluated. Results showed that planktonic $S$. aureus could not be clearly observed on the medium after treatment with $5.0 \mu \mathrm{mol} / \mathrm{L} \mathrm{SMC} \mathrm{for} 10 \mathrm{~min}\left(1.14 \mathrm{~J} / \mathrm{cm}^{2}\right)$. Bacterial cell DNA and protein were susceptible to SMC-mediated PDI, and cell membranes were found to be disrupted. Moreover, SMC-mediated PDI effectively reduced $8.31 \log \mathrm{CFU} / \mathrm{mL}$ of $S$. aureus on lettuce under $6.84 \mathrm{~J} / \mathrm{cm}^{2}$ radiant exposure (30 $\left.\mathrm{min}\right)$ with $100 \mu \mathrm{mol} / \mathrm{L}$ SMC, and PDI displayed a potent ability to restrain the weight loss as well as retard the changes of color difference of the lettuce during 7 day storage. The study will enrich our understanding of the inactivation of $S$. aureus by PDI, allowing for the development of improved strategies to eliminate bacteria in the food industry.
\end{abstract}

Keywords Photodynamic inactivation (PDI) $\cdot$ Staphylococcus aureus $\cdot$ Antibacterial mechanism $\cdot$ Lettuce

\section{Introduction}

Staphylococcus aureus is a common Gram-positive pathogen that has caused a large number of food safety incidents and has become a global health problem. Nearly half a million patients are affected by $S$. aureus annually, with 50,000 deaths each year attributed to this pathogen in the United States [1], and there were also about one million foodborne

Jingjing Wang

w_j2010@126.com

$\triangle$ Jie Ou

jou@shou.edu.cn

1 College of Food Science and Technology, Shanghai Ocean University, Shanghai 201306, China

2 Laboratory of Quality and Safety Risk Assessment for Aquatic Products on Storage and Preservation (Shanghai), Ministry of Agriculture and Rural Affairs, Shanghai 201306, China

3 Shanghai Engineering Research Center of Aquatic-Product Processing and Preservation, Shanghai 201306, China

4 Department of Food Science, Foshan University, Foshan 528000, China illnesses caused by $S$. aureus in 2010 [2]. Moreover, $S$. aureus commonly develop resistance to various antibiotics, including penicillin, methicillin and $\beta$-lactam antibiotics which are the most widely used groups of antibiotics $[3,4]$. In addition, the bacteria is widespread in the food industry and has become the main source of contamination by foodborne pathogens [2]. As a very popular vegetable, lettuce is eaten raw without heating or cooking, which is at risk of being contaminated by $S$. aureus [5]. Therefore, the sterilization and control of $S$. aureus are closely related to food safety and human health.

Currently, effective sterilization remains a challenge. In recent years, several non-thermal sterilization technologies have emerged including ultraviolet (UV), pulsed electric field (PEF), and high hydrostatic pressure (HHP) [6], which typically require high amounts of energy and are known to disrupt food flavor and nutrition. In addition, the most commonly used chemicals as food-contact surface sanitizers are chlorine, quaternary ammonium compounds, hydrogen peroxide compounds, and hydrogen peroxide [7]. While chlorine is used as a disinfectant for food processing and handling applications, chlorine compounds are corrosive to many metal surfaces (especially at higher temperatures), and 
the emergence of carcinogenic chlorides and new resistant pathogens are potential safety hazards [8, 9]. Hydroperoxides have limited applications in food, although they are widely used in the medical field. Therefore, it is necessary to find novel, safe, and effective sterilization technologies that do not result in drug resistance and can retain nutrients at optimal levels.

Photodynamic inactivation (PDI), as a novel and friendly sterilization technology, can not only effectively combat a variety of different pathogenic bacteria, but also has no genotoxicity and mutation [10]. Glueck has shown that PDI has a good effect on inactivating Escherichia coli on lettuce [11] In PDI, non-toxic dyes, also known as photosensitizers, are activated by harmless visible light to produce cytotoxic reactive oxygen species (ROS), causing fatal damage to target microorganisms $[12,13]$. Choosing appropriate photosensitizers for application in the food industry has become a research hotspot in the scientific community [14-17]. Chlorophyll sodium salt, a type of photosensitizer, is a broadspectrum tumor suppressor [18] that has been widely used in food additives and anti-anemia drugs, due to it being nontoxic and easily absorbed by humans [19]. Sodium magnesium chlorophyllin (SMC), a derivative of chlorophyll, has many advantages, such as good water solubility, high affinity to biomolecules, excellent photosensitivity and rapid elimination from the body with no adverse reactions. In addition, it is reported that PDI based on SMC $(10 \mu \mathrm{mol} / \mathrm{L})$ reduced the number of viable $S$. aureus by more than $6 \log \mathrm{CFU} /$ $\mathrm{mL}$ [20]. Therefore, SMC has potential application as a photosensitizer used in PDI to eradicate pathogens on food products.

The aim of the present study was to investigate the elimination ability of SMC-mediated blue LED PDI on S. aureus. The mechanisms of inactivation were assessed from the angles of DNA level, protein changes and morphological changes. Besides, the antibacterial potency of PDI against $S$. aureus on lettuce and the storage quality (weight loss and color) of lettuce was evaluated. This study will promote the potential applications of PDI technology as a novel and efficient non-thermal sterilization technology in the food industry.

\section{Experimental section}

\subsection{Bacterial strains and culture preparation}

A two-strain cocktail of $S$. aureus (ATCC 27661, standard strain; R11 isolated from raw pork in our lab) was used. Each strain (stored in $25 \%$ glycerol at $-80^{\circ} \mathrm{C}$ ) was streaked into Baird-Parker medium and cultured at $37^{\circ} \mathrm{C}$ for $24-36 \mathrm{~h}$ for activation. The activated $S$. aureus was inoculated into $9 \mathrm{~mL}$ tryptic soy broth (TSB; Beijing Land Bridge Technology
Co., Ltd, Beijing, China) for secondary activation, and cultured in a flask with continuous shaking $(180 \mathrm{rpm} / \mathrm{min})$ at $37{ }^{\circ} \mathrm{C}$ to the logarithmic growth phase, and then collected by centrifugation $(5000 \times g, 5 \mathrm{~min})$. The bacterial pellet was washed three times with normal saline $(0.85 \%)$ to obtain a cocktail of $\sim 8 \log \mathrm{CFU} / \mathrm{mL}$.

\subsection{LED system}

The light source used was blue LEDs (10 W, 455-460 nm, Getian Opto-Electronics Co., Ltd., China). The specification of the illumination device was $45 \mathrm{~cm} \times 45 \mathrm{~cm} \times 45 \mathrm{~cm}$, which was surrounded by a layer of black opaque material to prevent the entry of external light. The bacteria solutions in the 24-well plates were placed $5.0 \mathrm{~cm}$ away from the LED source. The irradiance $\left(3.80 \mathrm{~mW} / \mathrm{cm}^{2}\right)$ of the blue LED was measured using an energy meter console (PM100D, Newton, USA), and the radiant exposure was evenly distributed during the PDI process.

\subsection{Spectrum detection}

SMC solution was used to record the absorption spectrum of SMC, by a full wavelength scan between 350 and $700 \mathrm{~nm}$, using an ultraviolet-visible spectrophotometer (UV-6000PC, Shanghai Metash Instruments Co., Ltd, China). LED spectrum was collected using an Ocean Optics Maya 2000-Pro spectrometer.

\subsection{Experimental procedure of PDI}

Aliquots of bacterial suspension $\left(1 \times 10^{8} \log \mathrm{CFU} / \mathrm{mL}\right.$ in $0.85 \%$ saline) were mixed with an appropriate concentration of SMC $(0-5 \mu \mathrm{mol} / \mathrm{L})$, and incubated for $20 \mathrm{~min}$ at a shaker speed of $2 \mathrm{rpm}$. Then, $500 \mu \mathrm{L}$ of bacterial suspension was inoculated into a 24-well plate and exposed to light at different times (0-10 $\mathrm{min})$ and at different temperatures (4-37 ${ }^{\circ} \mathrm{C}$ ). In addition, $100 \mu \mathrm{L}$ of the suspension was spread on Baird-Parker medium and incubated for $24 \mathrm{~h}$ to evaluate the antibacterial effect of SMC-mediated PDI on S. aureus. The plate was then incubated at $37{ }^{\circ} \mathrm{C}$ for $24 \mathrm{~h}$, and the surviving cell population was counted and expressed as log $\mathrm{CFU} / \mathrm{mL}$ [21].

\subsection{Membrane permeability assay}

To evaluate the PDI-induced cell membrane damage, SYTO9 and propidium iodide (PI) were used with the LIVE/ DEAD BacLight kit (Molecular Probes, Thermo Fisher Scientific). Aliquots $(2 \mathrm{~mL})$ treated with $1.14 \mathrm{~J} / \mathrm{cm}^{2}$ radiant exposure and $9 \mu \mathrm{mol} / \mathrm{L} \mathrm{SMC}$ were immediately stained with the probes. The working concentrations of SYTO9 and PI were $5 \mu \mathrm{mol} / \mathrm{L}$ each. The cells stained with SYTO9/PI were 
incubated for $15 \mathrm{~min}$ at $25{ }^{\circ} \mathrm{C}$ in the dark, and then examined with a BD FACSVerse ${ }^{\mathrm{TM}}$ Flow Cytometer [22].

\subsection{Scanning electron microscopy (SEM)}

SEM was used to assess the bacterial morphology following PDI. The bacterial suspension sample was centrifuged at $10,000 \times g$ for $5 \mathrm{~min}$. The precipitate was mixed with $500 \mu \mathrm{L}$ of glutaraldehyde (2.5\%) and formaldehyde (4\%) in $0.1 \mathrm{~mol} / \mathrm{L}$ cocoate buffer for overnight at $4{ }^{\circ} \mathrm{C}$. Then, the sample was dehydrated from 30 to $100 \%$ using a continuous ethanol solution, and then coated with gold. Finally, the sample was scanned using a high-resolution tabletop SEM (SNE-4500 M, JEOL, Japan) at $5 \mathrm{kV}$ [23].

\subsection{Transmission electron microscopy (TEM)}

A transmission electron microscope (H-600, Hitachi, Japan) was used to explore the changes in morphological substances in the cells after PDI treatment. The method was improved based on Spurr AR [24]. The treated bacterial cells were sequentially fixed in $2 \%$ glutaraldehyde and $2 \% \mathrm{OsO} 4$, and then dehydrated in graded alcohol, and embedded in Epon 812 (American Electron Microscopy Science). Ultrathin sections $(70 \mathrm{~nm})$ were stained with uranyl acetate and lead citrate. Finally, the ultrastructure of bacteria was observed by TEM with a test voltage of $120 \mathrm{kV}$.

\subsection{Sodium dodecyl sulfate polyacrylamide gel electrophoresis (SDS-PAGE)}

The treated S. aureus suspension was centrifuged at $8000 \times g$ for $5 \mathrm{~min}$, and then the precipitation was resuspended in $0.85 \%$ normal saline and sonicated for $2 \mathrm{~min}$. After the samples were centrifuged, $20 \mu \mathrm{L}$ of supernatant was mixed with $5 \mu \mathrm{L}$ of loading buffer, and each sample was boiled for $10 \mathrm{~min}$. SDS-PAGE was performed on a discontinuous buffer system using a 12\% separation gel and 3\% stacking gel. The gel was stained with Coomassie Brilliant Blue (R-250) staining solution (45\% methanol, $10 \%$ acetic acid, and $0.25 \% \mathrm{R}-250$ ) and decolorized with methanol and acetic acid aqueous solution (methanol/acetic acid/water $=1: 1: 8$, $\mathrm{v} / \mathrm{v} / \mathrm{v})[25]$.

\subsection{DNA extraction and agarose gel electrophoresis}

Agarose gel electrophoresis was used to assess DNA damage. The SMC-mediated PDI-treated bacteria were centrifuged at $12,000 \times g$ for $2 \mathrm{~min}$. A TIANamp Bacterial DNA Kit (Tianjian Biotechnology Beijing Co., Ltd., China) was used to harvest bacterial DNA. Agarose gel electrophoresis $(2 \%)$ was used to separate the products, which were visualized with ethidium bromide staining. The Bio-Rad
ChemiDoc ${ }^{\mathrm{TM}}$ MP Imaging System (Bio-Rad, Hercules, CA, USA) was used to observe the results.

\subsection{Photodynamic inactivation of S. aureus on lettuce}

\subsubsection{Experimental procedure of PDI on lettuce}

Lettuce was purchased from a local supermarket in Shanghai. The lettuce leaves were cut into $4 \mathrm{~cm} \times 4 \mathrm{~cm}$ pieces using a sterile knife. It was then stored at $4{ }^{\circ} \mathrm{C}$ and used within $24 \mathrm{~h}$. To remove the native microorganisms, the lettuce leaves were UV sterilized for $1 \mathrm{~h}$. Then, $100 \mu \mathrm{L}$ of the S. aureus cocktail and SMC solution $(50,60,70,80,90$, and $100 \mu \mathrm{mol} / \mathrm{L}$ ) were inoculated on the surface of lettuce leaves, and subjected to PDI treatment for $30 \mathrm{~min}$ after $40 \mathrm{~min}$ incubation. Samples treated without light and SMC, light-only, or SMC-only were chosen as negative controls $(\mathrm{L}-\mathrm{S}-)$, radiant exposure control $(\mathrm{L}+\mathrm{S}-)$, and $\mathrm{SMC}$ control $(\mathrm{L}-\mathrm{S}+)$.

\subsubsection{Detection of weightlessness rate}

Fresh lettuces that had been inoculated with $S$. aureus were divided into two groups: control and PDI treatment with SMC $\left(100 \mu \mathrm{M}, 6.84 \mathrm{~J} / \mathrm{cm}^{2}\right)$. Weight loss in the total lettuce leaves in each group were tested every other day to calculate the weightlessness rate at room temperature and repeated three times.

Weightlessness rate $=\left(W_{0}-W_{t}\right) / W_{0} \times 100 \%$,

$W_{0}$ is the weight of total lettuce leaves on the first day, and $W_{t}$ is the weight of total lettuce leaves every day.

\subsubsection{Color analysis}

The color of the samples was measured using a colorimetric spectrophotometer (NR20XE Precision Colorimeter). The $L^{*}, a^{*}$, and $b^{*}$ values were recorded, and the values of total color difference $(\Delta E)$ were calculated using the equation below [26]. Images of the samples were also taken:

$\Delta E=\sqrt{\left(L_{t}^{*}-L_{0}^{*}\right)^{2}+\left(a_{t}^{*}-a_{0}^{*}\right)^{2}+\left(b_{t}^{*}-b_{0}^{*}\right)^{2}}$,

where $L_{0}^{*}, a_{0}^{*}$, and $b_{0}^{*}$ are the $L^{*}, a^{*}$, and $b^{*}$ values of lettuce for zero days, whereas $L_{t}^{*}, a_{t}^{*}$, and $b_{t}^{*}$ represent the $L^{*}, a^{*}$, and $b^{*}$ values of lettuce with different storage times.

\subsection{Statistical analysis}

Values are reported as mean \pm standard deviation (SD) from three separate experiments. The value differences $(P<0.05)$ 
was compared by one-way analysis using SPSS 17.0 software (SPSS Inc., Chicago, IL).

\section{Results}

\subsection{Photosensitizing device and light source}

A compact photosensitive laboratory-scale inactivation device was constructed, with LED lights and a space for a 24-well plate (Fig. 1). Samples were positioned at the center of the chamber, $5 \mathrm{~cm}$ away from the LED light source. In this study, the emission spectrum of the blue LED and the absorption spectrum of the SMC were detected, and there was an overlap between 443 and $485 \mathrm{~nm}$ of the two spectra (Fig. 2).

\subsection{Antibacterial effects of the SMC-mediated PDI against S. aureus}

The effects of the photosensitizer concentration on the PDI against $S$. aureus are shown in Fig. 3a. Non-irradiated cells of the negative control group were $\sim 8.30 \log \mathrm{CFU} / \mathrm{mL}$, and no significant changes were observed in samples irradiated with $1.140 \mathrm{~J} / \mathrm{cm}^{2}(\mathrm{~L}+\mathrm{S}-)$ or $9 \mu \mathrm{mol} / \mathrm{L} \mathrm{SMC}(\mathrm{L}-\mathrm{S}+)$. However, $S$. aureus showed a gradual decrease with increasing SMC under radiant exposure, and a significant decrease was observed at $1 \mu \mathrm{mol} / \mathrm{L}$ SMC with $1.140 \mathrm{~J} / \mathrm{cm}^{2}$ radiant exposure. Notably, $S$. aureus was significantly $(P<0.05)$ decreased by $4.99 \log \mathrm{CFU} / \mathrm{mL}$ at $5 \mu \mathrm{mol} / \mathrm{L}$ SMC. With the further increase of SMC to $9 \mu \mathrm{mol} / \mathrm{L}$, the PDI treatment showed enhanced and dose-dependent bactericidal activity under $1.14 \mathrm{~J} / \mathrm{cm}^{2}$ radiant exposure.

The effects of radiant exposure dosage on inactivating S. aureus are shown in Fig. 3b. Compared with the control, S. aureus exhibited a significant decrease with increasing radiant exposure. After $0.225 \mathrm{~J} / \mathrm{cm}^{2}$ radiant exposure with

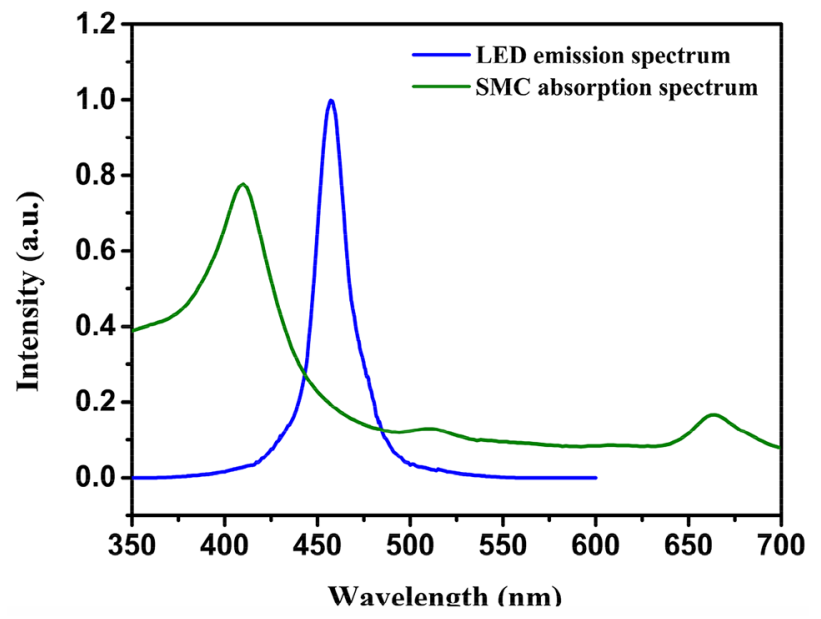

Fig. 2 Absorption spectrum of sodium magnesium chlorophyllin and emission spectrum of blue LED

$5 \mu \mathrm{mol} / \mathrm{L}$ SMC, $S$. aureus cells were reduced to $6.30 \mathrm{log}$ $\mathrm{CFU} / \mathrm{mL}(P<0.05)$. As the LED radiant exposure dosage increased from 0.225 to $1.14 \mathrm{~J} / \mathrm{cm}^{2}$, bacterial cells showed a significant and continuous decrease. Moreover, no visible colonies of $S$. aureus were visible on LB agar plates under $2.28 \mathrm{~J} / \mathrm{cm}^{2}$ (10 $\mathrm{min}$ ) radiant exposure. Therefore, PDI-induced inactivation of $S$. aureus is dependent on the photosensitizer concentration and radiant exposure dosage.

The effects of treatment temperature on inactivating $S$. aureus are shown in Fig. 3c. Compared with the negative control, $S$. aureus cells were significantly reduced at all temperatures $\left(37^{\circ} \mathrm{C}, 25^{\circ} \mathrm{C}, 10^{\circ} \mathrm{C}\right.$, and $\left.4{ }^{\circ} \mathrm{C}\right)$ under $1.14 \mathrm{~J} /$ $\mathrm{cm}^{2}$ radiant exposure with $3 \mu \mathrm{mol} / \mathrm{L}$ SMC. However, $S$. aureus exhibited relatively faster $(P<0.05)$ susceptibility to PDI at $37{ }^{\circ} \mathrm{C}$ than at $4{ }^{\circ} \mathrm{C} ; \mathrm{S}$. aureus cells were reduced by $5.23 \log \mathrm{CFU} / \mathrm{mL}$ at $37^{\circ} \mathrm{C}$, and by $3.70 \log \mathrm{CFU} / \mathrm{mL}$ at $4{ }^{\circ} \mathrm{C}$.
Fig. 1 Photodynamic inactivation apparatus
Light box device

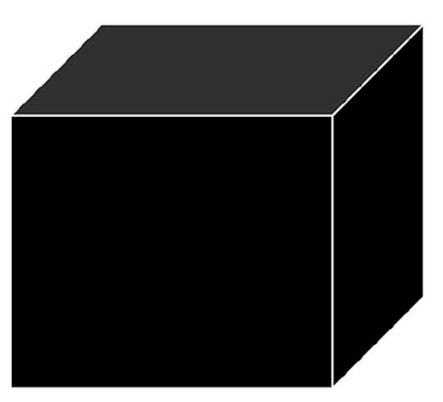

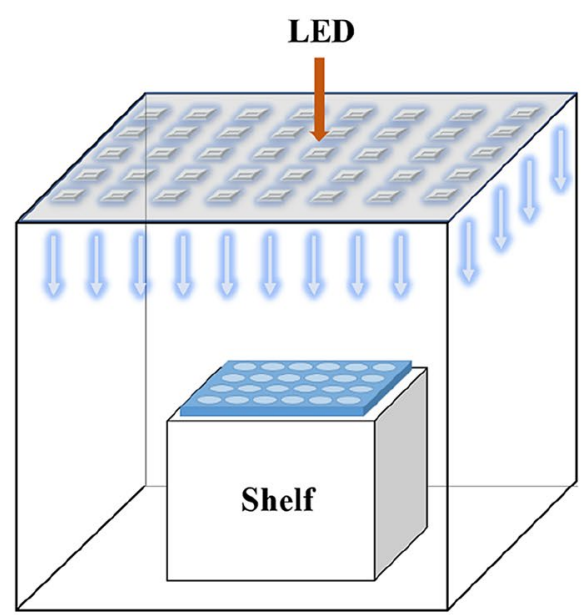



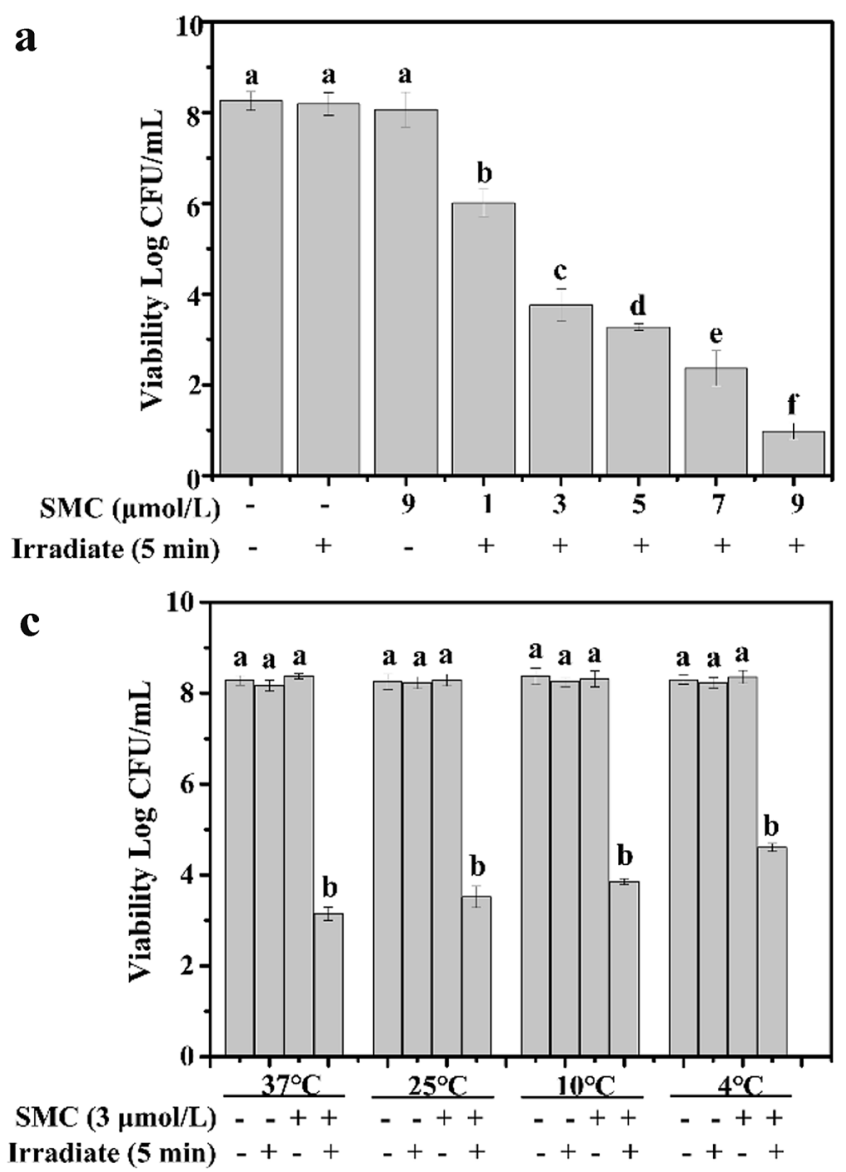

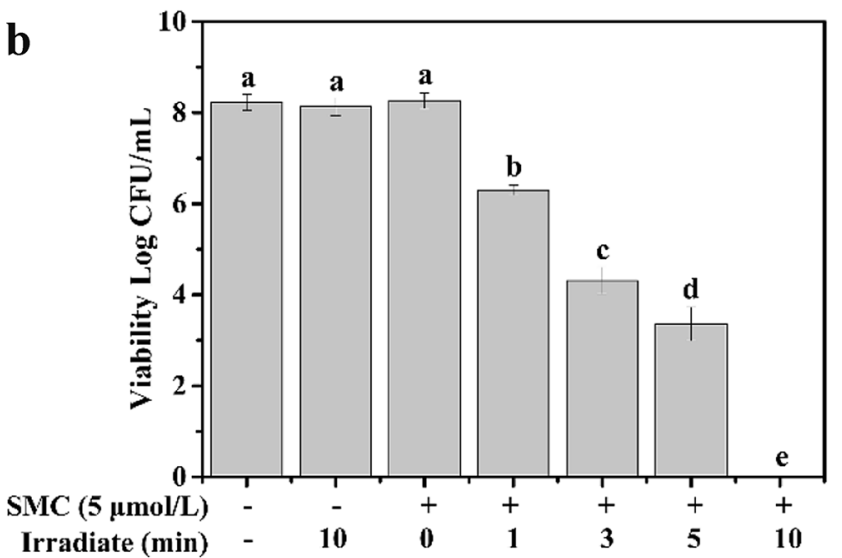

Fig. 3 Effects of SMC-mediated PDI on the viability of S. aureus a SMC concentration; $\mathbf{b}$ illumination time; $\mathbf{c}$ treatment temperatures

\subsection{Membrane permeability assay}

SYTO9/PI mixed probes were used to assess cell membrane damage using flow cytometry. SYTO9 enters the intact or damaged cell membrane, while PI only penetrates the damaged membrane [27]. When SYTO9 coexists with PI in cells, the intensity of SYTO9 is reduced. Compared with the negative control (Fig. 4a), no significant changes were observed in samples irradiated with $1.140 \mathrm{~J} / \mathrm{cm}^{2}(\mathrm{~L}+\mathrm{S}-)$ (Fig. 4b) or incubated with $9 \mu \mathrm{mol} / \mathrm{L}$ SMC (L-S+) (Fig. 4c). In addition, the permeability of $S$. aureus increased to $80.42 \%$ under $1.14 \mathrm{~J} / \mathrm{cm}^{2}$ radiant exposure with $9 \mu \mathrm{mol} / \mathrm{L} \mathrm{SMC} \mathrm{(Fig.} 4 \mathrm{~d}$ ). These results showed that PDI disrupted the cell membrane structure.

\subsection{Surface morphology changes of S. aureus}

In the control group, the cell surfaces were smooth and the bacteria were plump and round (Fig. 5a-c), as visualized by SEM. After SMC-mediated PDI treatment, the cell surfaces were distorted with slight grooves (Fig. 5d, e). Moreover, obviously rupture of the part of bacteria was observed when the SMC was increased to $9 \mu \mathrm{mol} / \mathrm{L}$ (Fig. 5f).

\subsection{Internal structure changes of S. aureus}

To obtain conclusive evidence that the SMC-mediated PDI causes changes in cell structures, TEM was used to photograph the cell ultrastructure (Fig. 6). There was no obvious change in the bacteria in the negative control group (Fig. 6a). However, PDI-treated samples had damaged internal structures, in which the cytoplasm was disordered, degraded, and had even been leaked (Fig. 6b-d). With the SMC at $9 \mu \mathrm{mol} / \mathrm{L}$, the cytoplasmic strength of $S$. aureus was significantly weakened, indicating that the degree of cytoplasmic destruction was greatly enhanced (Fig. 6d).

\subsection{Protein and DNA changes of S. aureus}

SDS-PAGE was used to evaluate protein damage following SMC-mediated PDI against $S$. aureus. As shown in Fig. 7a, all control samples showed similar protein band numbers and intensities (lanes 1, 2, and 3) with $1.14 \mathrm{~J} / \mathrm{cm}^{2}$ (5 min) 

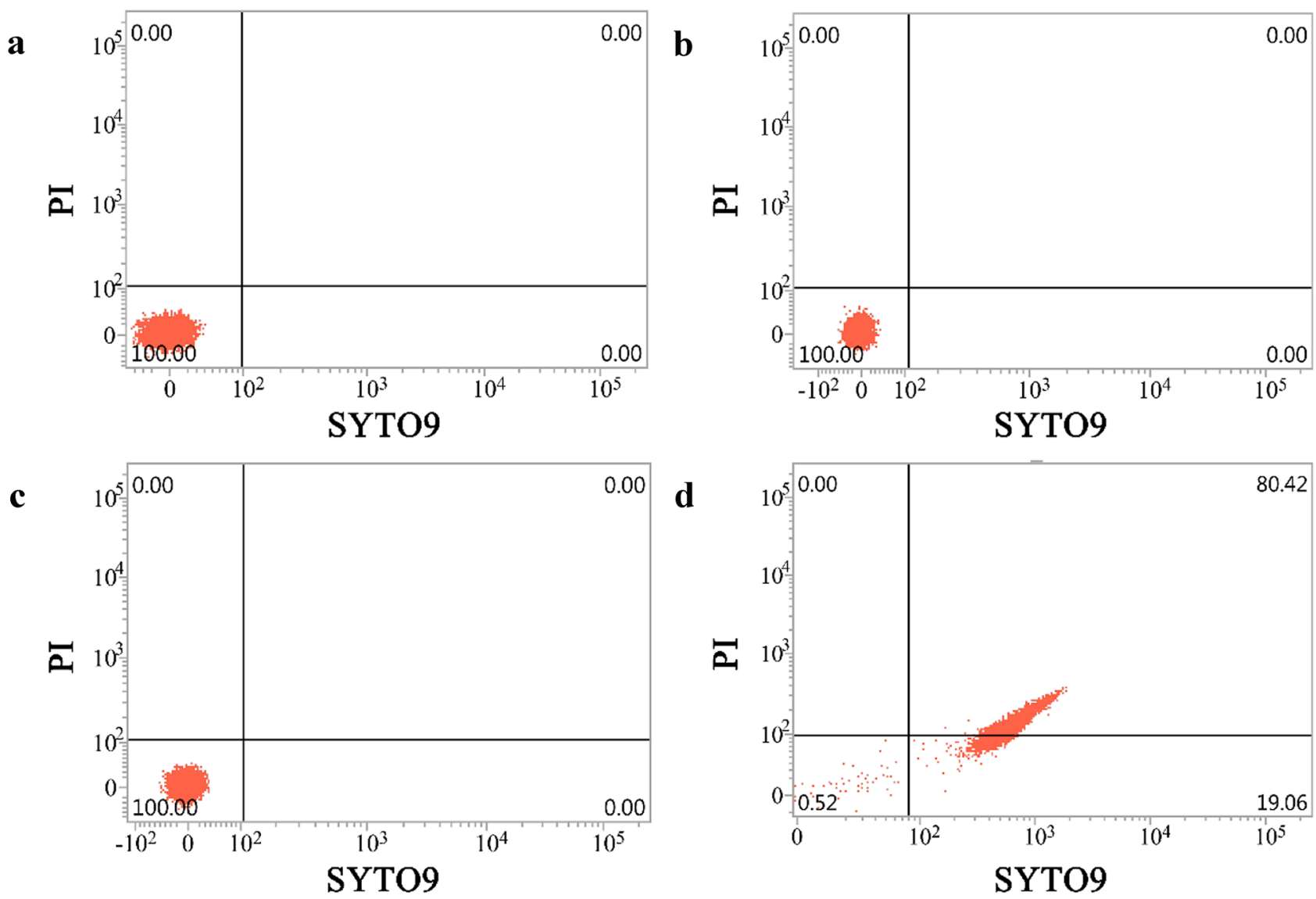

Fig. 4 Membrane permeability of $S$. aureus was measured using flow cytometry with SYTO9 and PI a L-S-; b L+S-; c L-S+; d $9 \mu$ mol/L $\operatorname{SMC}\left(1.14 \mathrm{~J} / \mathrm{cm}^{2}\right)$

illumination $(\mathrm{L}+\mathrm{S}-)$ or $9 \mu \mathrm{mol} / \mathrm{L} \mathrm{SMC}(\mathrm{L}-\mathrm{S}+)$, indicating that individual radiant exposure or SMC did not have negative effects on protein integrity. With an increase in the SMC concentration from 5 to $9 \mu \mathrm{mol} / \mathrm{L}$, SMC-mediated PDI induced a slight decrease in the band intensity of proteins under $1.14 \mathrm{~J} /$ $\mathrm{cm}^{2}$ radiant exposure, notably the $\sim 60 \mathrm{kDa}$ and $\sim 45 \mathrm{kDa}$ proteins.

DNA is the basis of the normal physiological activities of bacteria. Once DNA is damaged, bacteria cannot grow normally. The effects of SMC-mediated PDI on the genomic DNA of $S$. aureus cocktails are shown in Fig. 7b. The genomic DNA of $S$. aureus extracted from all controls did not have any DNA lysis (lanes 1, 2, and 3), whereas the brightness of DNA bands (lanes 7 and 8) was strengthened as the concentration of SMC increased from $7 \mu \mathrm{mol} / \mathrm{L}\left(1.14 \mathrm{~J} / \mathrm{cm}^{2}\right)$ to $9 \mu \mathrm{mol} / \mathrm{L}(1.14 \mathrm{~J} /$ $\mathrm{cm}^{2}$ ), indicating that significant degradation of genomic DNA had occurred.

\subsection{Photodynamic inactivation of S. aureus on lettuce}

Approximately $3.45 \log \mathrm{CFU} / \mathrm{mL}$ of $S$. aureus were killed when the concentration of SMC reached $60 \mu \mathrm{mol} / \mathrm{L}$ $\left(6.84 \mathrm{~J} / \mathrm{cm}^{2}\right)$ (Fig. 8a). When SMC reached $100 \mu \mathrm{mol} / \mathrm{L}$, $S$. aureus was completely killed $(\sim 8.31 \log \mathrm{CFU} / \mathrm{mL})$. Figure $8 \mathrm{~b}$ shows that the weightlessness rate of lettuce in the PDI-treatment group was significantly lower than that in the control group on the day following treatment. In addition, we calculated the total color difference $(\Delta \mathrm{E})$ for lettuce to characterize the changes in color caused by storage (Fig. 8c). The changes in the PDI-treatment and control groups were not obvious in the first 3 days. As storage time increased, the $\Delta \mathrm{E}$ of the control group reached 26.24, which was about 11 units higher than the PDItreatment group on the fifth day. When the storage time 
a

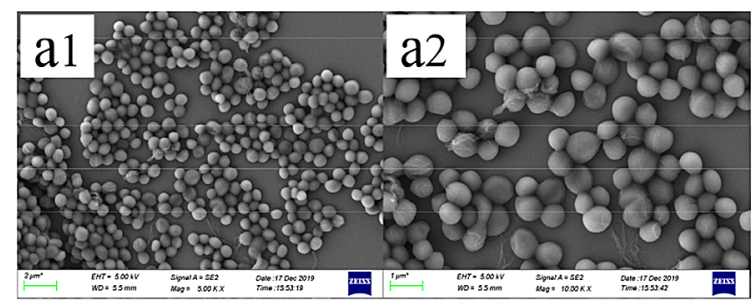

b

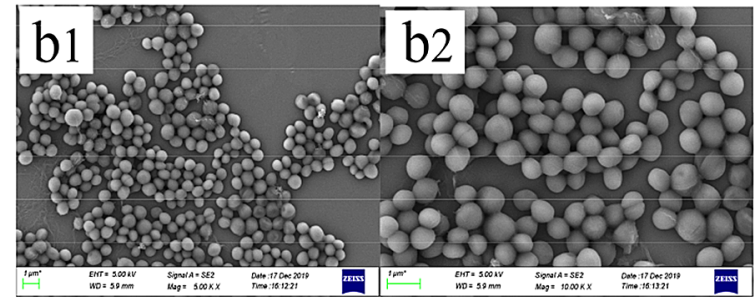

c

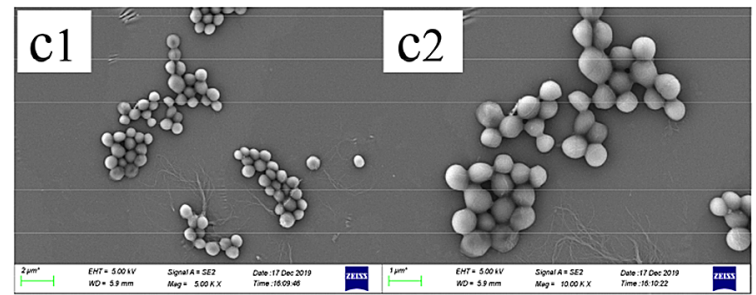

d

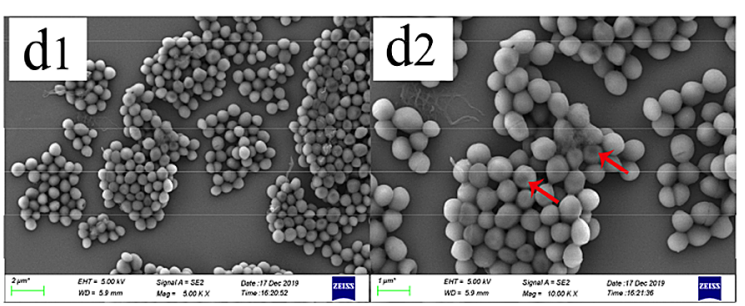

e

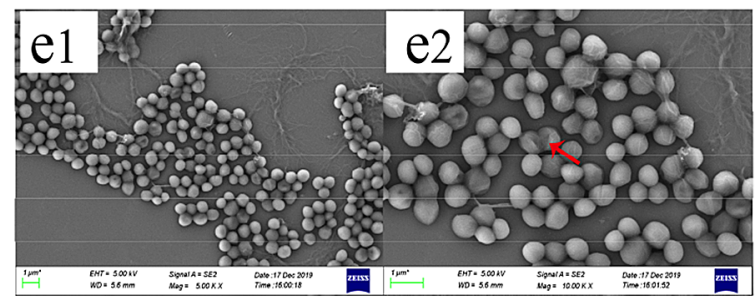

f

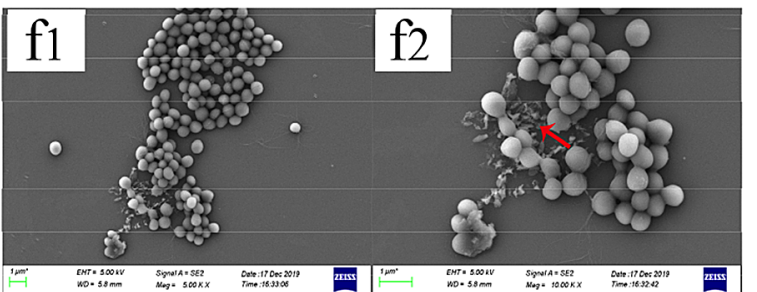

Fig. 5 Observation of cell surface changes of $S$. aureus by SEM. a L-S-; b L+S-; c L-S+; d $1 \mu$ mol/L SMC and $1.14 \mathrm{~J} / \mathrm{cm}^{2}(5 \mathrm{~min})$; e $5 \mu \mathrm{mol} / \mathrm{L} \mathrm{SMC}$ and $1.14 \mathrm{~J} / \mathrm{cm}^{2}(5 \mathrm{~min}) ; \mathbf{f} 9 \mu \mathrm{mol} / \mathrm{L} \mathrm{SMC}$ and $1.14 \mathrm{~J} / \mathrm{cm}^{2}(5 \mathrm{~min})$

Fig. 6 Observation of ultrastructural changes of $S$. aureus by TEM. a L-C-; b $1 \mu \mathrm{mol} / \mathrm{L}$ $\mathrm{SMC}$ and $1.14 \mathrm{~J} / \mathrm{cm}^{2}(5 \mathrm{~min}) ; \mathbf{c}$ $5 \mu \mathrm{mol} / \mathrm{L} \mathrm{SMC}$ and $1.14 \mathrm{~J} / \mathrm{cm}^{2}$ $(5 \mathrm{~min}) ; \mathbf{d} 9 \mu \mathrm{mol} / \mathrm{L} \mathrm{SMC}$ and $1.14 \mathrm{~J} / \mathrm{cm}^{2}$ (5 min); a

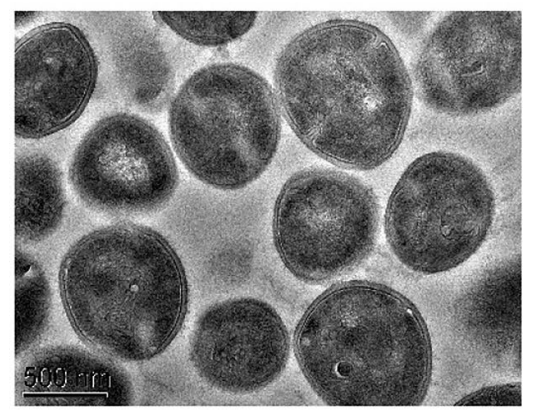

c

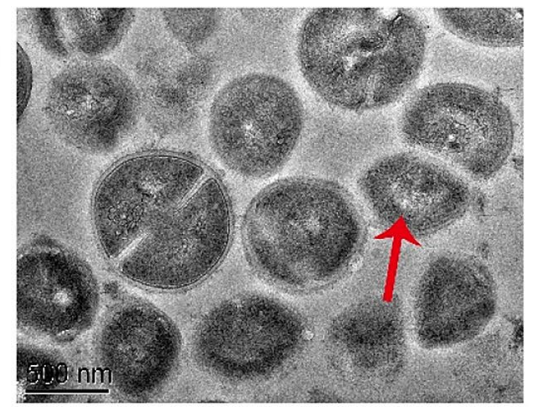

b

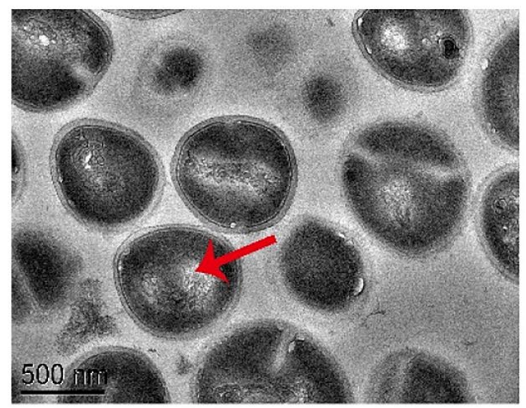

d

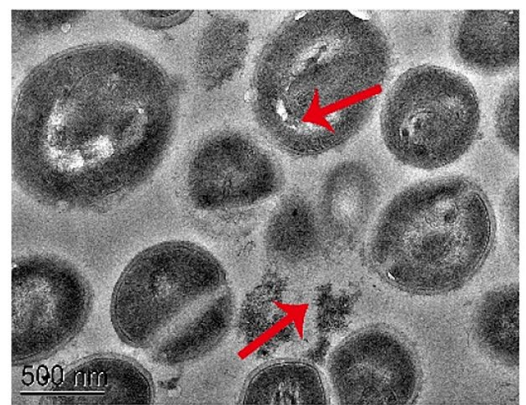

reached the seventh day, the color of lettuce in the control group was obviously brown (Fig. 8d), and the $\Delta$ E reached 37.47, while the PDI-treatment group reached 24.40. The technology of SMC-mediated PDI delayed the browning of lettuce in 7 days of storage (Fig. 8c, d).

\section{Discussion}

PDI is used for food decontamination as it can inactivate bacteria, fungi, and yeasts, regardless of whether they are 
a Irradiate $(5 \min )-++++++$

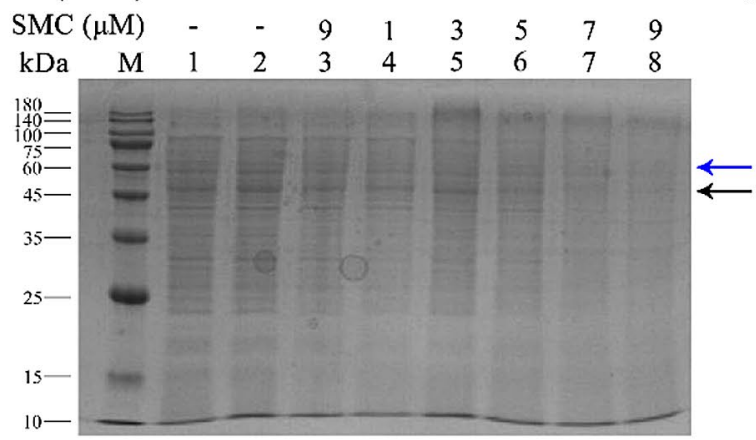

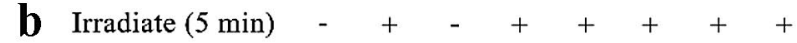

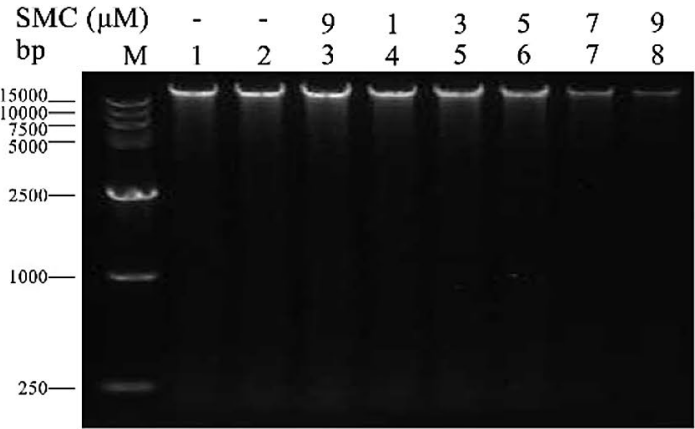

Fig. 7 Effects of SMC-mediated PDI on total protein and DNA of S. aureus. a M: protein Marker (10-180 kDa); b total bacterial DNA was extracted and separated by $1 \%$ agarose gel electrophoresis. M: Marker, DL 15000

$\mathbf{a}$

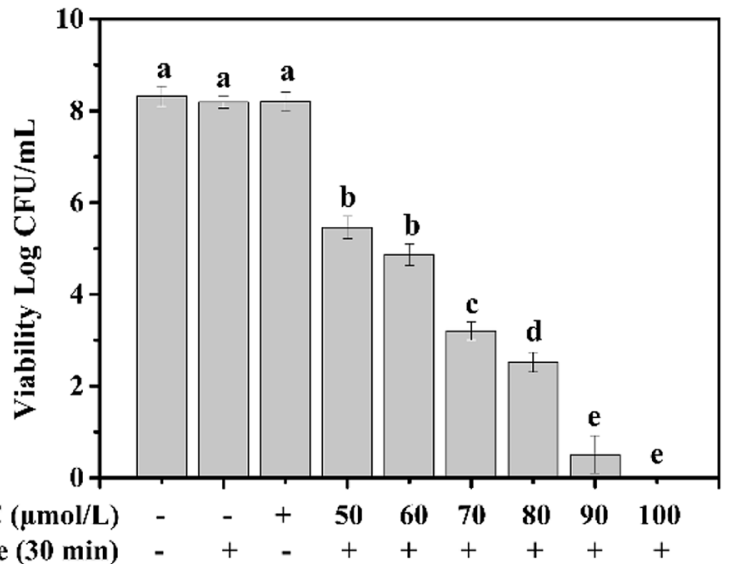

C

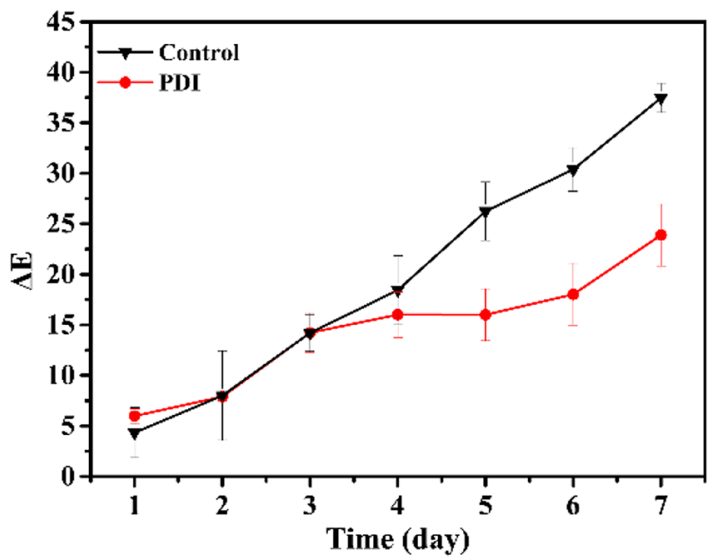

b

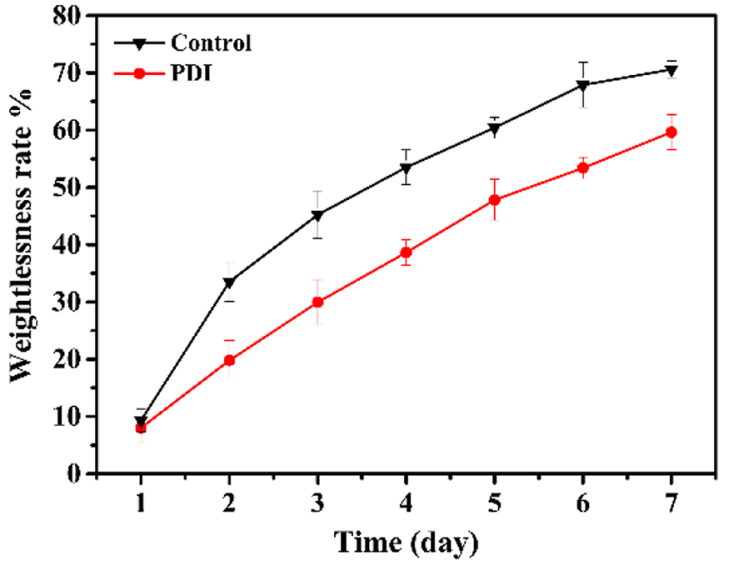

d
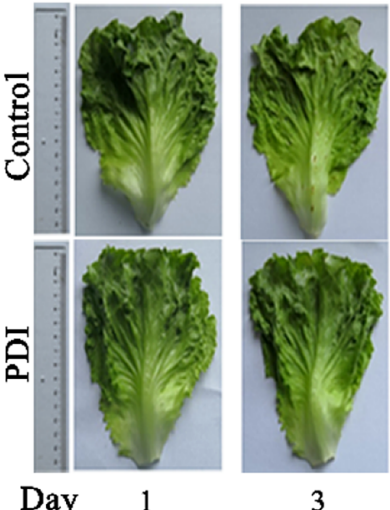

3

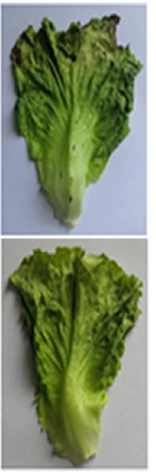

5

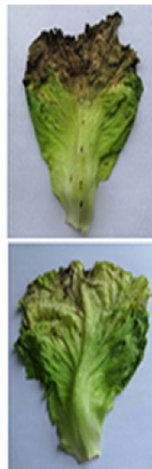

7

Fig. 8 Effects of SMC-mediated PDI against S. aureus on lettuce a bactericidal effect; $\mathbf{b}$ weightlessness rate; $\mathbf{c}$ total color difference; $\mathbf{d}$ photograph of lettuce

resistant to conventional antibacterial agents [28]. SMC is water-soluble and has been approved as a food additive, E140. Its high biocompatibility has a great potential application in photodynamic inactivation in the food industry $[10,16]$. LED technology is environmentally friendly, low energy consumption and excellent safety, which is widely used in the field of light-based food processing [29]. Blue region of VIS light has higher inactivation effect on microorganisms compared to other regions of VIS light [30]. In this study, SMC-mediated PDI exhibited high inactivation efficiency against $S$. aureus (Fig. 3), which can be attributed to the generation of ROS from the PDI leading to the 
inactivation of S. aureus [31]. Notably, inactivation of bacteria by PDI was found to be higher at room temperature than at refrigeration temperature (Fig. 3c). This finding differs from our previous study $[6,25]$, which showed that the treatment temperatures of curcumin-mediated PDI did not influence the inactivation of $L$. monocytogenes or $V$. parahaemolyticus. This phenomenon may be attributed to the higher degree of cellular activity at higher temperature [32]. Higher cellular viability leads to higher metabolism and thus to a higher uptake of SMC, which leads to a higher rate of bacterial inactivation [33].

It is generally believed that the internal or external structure of bacterial cells changes after radiant exposure, and in the present study, flow cytometry and SEM were used to monitor potential cell membrane disturbances. SYTO9 can enter cells through intact and damaged membranes, while PI only penetrates the damaged plasma membrane [27, 34], and flow cytometry revealed that $80.42 \%$ of bacteria underwent apoptosis following SMC-mediated PDI, indicating cell membrane damage (Fig. 4d). This was supported by the relatively integrated cell structures observed by SEM (Fig. 5). This result was significantly different to the morphological changes that occurred in the Gram-negative $V$. parahaemolyticus treated with PDI, which showed a large number of ruptured cells [6]. TEM was employed to investigate internal structural changes, which revealed that the vacuolar space increased under $1.14 \mathrm{~J} / \mathrm{cm}^{2}$ radiant exposure with $9 \mu \mathrm{mol} / \mathrm{L}$ SMC. The results obtained during this study were consistent with the observations reported in a similar study investigating the effects of PDI on bacteria [25].

To further evaluate the SMC-mediated PDI changes to internal cell structures, irradiated and non-irradiated $S$. aureus cells were examined by agarose gel electrophoresis (Fig. 7b) and SDS-PAGE (Fig. 7a). Cellular DNA is considered the main target of ROS produced by LED illumination [35]. In this study, the DNA and protein bands of $S$. aureus showed an apparent degradation effect exposed to $1.14 \mathrm{~J} / \mathrm{cm}^{2}$ radiant exposure in combination with $9 \mu \mathrm{mol} / \mathrm{L}$ SMC. ROS attack a variety of biomolecules, such as destructing DNA (especially guanine bases) and inactivating proteins by attacking sulfur containing and aromatic amino acids [36]. PDI causes breaks in single-stranded and double-stranded DNA, and the disappearance of the super-coiled fraction of plasmid DNA in bacterium [37]. In addition, results showed that SMC-mediated PDI might cause protein damage and even degradation (Fig. 7a). Proteins are easily damaged due to their high abundance and rapid reaction rate with ROS. ROS generated by PDI can interact with various amino acid residues in the proteins, and cause the loss of histidine residues and cleavage of peptide bonds. Sulfur-containing amino acids, including cysteine and methionine, are particularly sensitive [36]. Similar changes in DNA and protein structure have been observed in previous studies [25, 38]. The difference in cell wall structure between Gram-negative and Grampositive bacteria is considered the main factor affecting the efficiency of PDI [34], as the main target of PDI is considered to be the external structure of bacteria [39]. However, Ghate et al. [30] showed that LED illumination had very few differences between bacterial strains. There are many factors that affect the inactivation efficiency of PDI, including bacterial strain, photosensitizer characteristics (such as hydrophilicity or hydrophobicity), and emission (light) and absorption (photosensitizer) spectrum overlap [40].

More importantly, SMC-mediated PDI effectively inactivated S. aureus on lettuce. Lettuce is one of the most common vegetables worldwide that can be eaten raw, and it is very susceptible to $S$. aureus infection during processing and storage [5], which poses a threat to human health. In the present study, the sterilization time was set to $30 \mathrm{~min}$, as per the method of Yilin Lin [41], which greatly maintained the freshness of the lettuce after picking. The inactivation of $S$. aureus on lettuce reached $\sim 8.31 \log \mathrm{CFU} / \mathrm{mL}$ under $6.84 \mathrm{~J} /$ $\mathrm{cm}^{2}$ radiant exposure $(30 \mathrm{~min})$ with $100 \mu \mathrm{mol} / \mathrm{L} \mathrm{SMC}$. The bacteria on lettuce are more difficult to inactivate than those in aqueous solution, largely due to the texture and characteristics of lettuce, including: (1) lettuce has a rough surface, in which the crevices, pores, and cracks harbor microorganisms [42]; (2) hydrophobicity and bacterial surface charge drive the attachment tendency of microorganism on the lettuce surface, if loose attachment on the fresh produce surface is considered [43]; (3) aggregation of $S$. aureus on the surface promotes additional attachment strength, thus increasing the difficulty of inactivation [44]. In addition, lettuce is rich in vitamins, which are important antioxidants, and some of the ROS produced by PDI may be inhibited by them [45]. Regardless, PDI showed a good sterilization effect on lettuce. Leaf edge browning is the main factor affecting lettuce marketability [46]. Enzymatic browning is a widespread color reaction occurring in vegetables, which involves a variety of interactions of oxygen, phenolic compounds, and PPO [47]. In addition, bacteria occur on vegetable surfaces may enter the host at damaged areas or natural openings and it may produce plant cell wall-degrading enzymes leading to spoilage [48]. Overall change in color $(\Delta E)$ showed that the browning rate of lettuce with PDI treatment was lower than control, which might be attributed to the PDI delaying the browning rate by inactivating S. aureus. Moreover, weight loss is principally attributed to lettuce respiration and superficial dehydration which have negative effect in general appearance of leafy greens, such as wilting, shrinking and deteriorate [49]. PDI displayed a potent ability $(P<0.05)$ to restrain the weight loss (Fig. 8b). These results provided the evidence that PDI with SMC have a potential for food sterilization. 


\section{Conclusions}

This study showed that SMC-mediated PDI effectively inactivated planktonic $S$. aureus cells. S. aureus DNA and protein were susceptible to SMC-mediated PDI, and the cell membranes were disrupted by the treatment. Moreover, PDI displayed a potent ability to restrain the weight loss as well as retard the changes of color difference of the lettuce. Therefore, SMC-mediated PDI is an effective technology to control pathogenic microorganisms, and this study provides novel insight into its application in food preservation.

Acknowledgements This study was supported by the National Key R\&D Program of China (2018YFC1602205).

\section{Declarations}

Conflict of interest There are no conflicts to declare.

\section{References}

1. Liu, C. Y., Shi, C., Li, M. Z., Wang, M. Y., Ma, C. P., \& Wang, Z. H. (2019). Rapid and simple detection of viable foodborne pathogen Staphylococcus aureus. Frontiers in Chemistry, 7, 7.

2. W. H. Organization (2015) WHO estimates of the global burden of foodborne diseases: foodborne disease burden epidemiology reference group 2007-2015.

3. Grundmann, H., Aires-De-Sousa, M., Boyce, J., \& Tiemersma, E. (2006). Emergence and resurgence of meticillin-resistant Staphylococcus aureus as a public-health threat. The Lancet, 368(9538), 874-885.

4. Morikawa, K., Maruyama, A., Inose, Y., Higashide, M., Hayashi, H., \& Ohta, T. (2001). Overexpression of sigma factor, sigma(B), urges Staphylococcus aureus to thicken the cell wall and to resist beta-lactams. Biochemical and Biophysical Research Communications, 288(2), 385-389.

5. Wei, S., Park, B.-J., Seo, K.-H., \& Oh, D.-H. (2016). Highly efficient and specific separation of Staphylococcus aureus from lettuce and milk using Dynabeads protein G conjugates. Food Science and Biotechnology, 25(5), 1501-1505.

6. Chen, B. W., Huang, J. M., Li, H. H., Zeng, Q. H., Wang, J. J., Liu, H. Q., Pan, Y. J., \& Zhao, Y. (2020). Eradication of planktonic Vibrio parahaemolyticus and its sessile biofilm by curcuminmediated photodynamic inactivation. Food Control, 113, 10.

7. Basaran, P. (2011). Inhibition effect of belzalkonium chloride treatment on growth of common food contaminating fungal species. Journal of Food Science and Technology, 48(4), 515-519.

8. Kumarasamy, K. K., Toleman, M. A., Walsh, T. R., Bagaria, J., Butt, F., Balakrishnan, R., Chaudhary, U., Doumith, M., Giske, C. G., Irfan, S., Krishnan, P., Kumar, A. V., Maharjan, S., Mushtaq, S., Noorie, T., Paterson, D. L., Pearson, A., Perry, C., Pike, R., ... Woodford, N. (2010). Emergence of a new antibiotic resistance mechanism in India, Pakistan, and the UK: a molecular, biological, and epidemiological study. The Lancet Infectious Diseases, 10(9), 597-602.

9. Singh, N., Singh, R. K., Bhunia, A. K., \& Stroshine, R. L. (2002). Effect of inoculation and washing methods on the efficacy of different sanitizers against Escherichia coli O157: H7 on lettuce. Food Microbiology, 19(2-3), 183-193.
10. Zudyte, B., \& Luksiene, Z. (2019). Toward better microbial safety of wheat sprouts: chlorophyllin-based photosensitization of seeds. Photochemical \& Photobiological Sciences, 18(10), 2521-2530.

11. Glueck, M., Schamberger, B., Eckl, P., \& Plaetzer, K. (2017). New horizons in microbiological food safety: photodynamic decontamination based on a curcumin derivative. Photochemical \& Photobiological Sciences, 16(12), 1784-1791.

12. Al-Shammery, D., Michelogiannakis, D., Ahmed, Z. U., Ahmed, H. B., Rossouw, P. E., Romanos, G. E., \& Javed, F. (2019). Scope of antimicrobial photodynamic therapy in orthodontics and related research: a review. Photodiagnosis and Photodynamic Therapy, $25,456-459$.

13. Ran, T., Fang, Z., Qing-Juan, T., Chuan-Shan, X., Zhi-Jing, N., \& Xiang-Hong, M. (2019). Effects of curcumin-based photodynamic treatment on the storage quality of fresh-cut apples. Food Chemistry, 274, 415-421.

14. Liu, F., Li, Z. J., Cao, B. B., Wu, J., Wang, Y. M., Xue, Y., Xu, J., Xue, C. H., \& Tang, Q. J. (2016). The effect of a novel photodynamic activation method mediated by curcumin on oyster shelf life and quality. Food Research International, 87, 204-210.

15. Chen, B., Huang, J., Liu, Y., Liu, H., Zhao, Y., \& Wang, J. J. (2021). Effects of the curcumin-mediated photodynamic inactivation on the quality of cooked oysters with Vibrio parahaemolyticus during storage at different temperature. International Journal of Food Microbiology, 345, 109152-109152.

16. Paskeviciute, E., Zudyte, B., \& Luksiene, Z. (2019). Innovative nonthermal technologies: chlorophyllin and visible light significantly reduce microbial load on basil. Food Technology and Biotechnology, 57(1), 126-132.

17. Lijun, T., Huihui, L., Bowen, C., Jiaming, H., Yufeng, L., Huaming, Z., Haiquan, L., Yong, Z., \& Jing, W. J. (2021). Dual-species biofilms formation of Vibrio parahaemolyticus and Shewanella putrefaciens and their tolerance to photodynamic inactivation. Food Control, 125, 107983.

18. Carter, O., Bailey, G. S., \& Dashwood, R. H. (2004). The dietary phytochemical chlorophyllin alters e-cadherin and beta-catenin expression in human colon cancer cells. Journal of Nutrition, 134(12), 3441S-3444S.

19. Wang, J., Liu, L. J., Liu, B., Guo, Y., Zhang, Y. Y., Xu, R., Wang, S. X., \& Zhang, X. D. (2010). Spectroscopic study on interaction of bovine serum albumin with sodium magnesium chlorophyllin and its sonodynamic damage under ultrasonic irradiation. Spectrochimica Acta Part A: Molecular and Biomolecular Spectroscopy, 75(1), 366-374.

20. Hasenleitner, M., \& Plaetzer, K. (2020). In the right light: photodynamic inactivation of microorganisms using a LED-based illumination device tailored for the antimicrobial application. Antibiotics-Basel, 9(1), 13.

21. Xi, D., Shuze, T., Qian, W., Juan, T., Riley, W. W., \& Zhenqiang, C. (2016). Inactivation of Vibrio parahaemolyticus by antimicrobial photodynamic technology using methylene blue. Journal of the Science of Food and Agriculture, 96(5), 1601-1608.

22. Kim, M. J., \& Yuk, H. G. (2017). Antibacterial mechanism of 405-nanometer light-emitting diode against salmonella at refrigeration temperature. Applied and Environmental Microbiology, 83(5), 14.

23. Hu, J. M., Lin, S. L., Tan, B. K., Hamzah, S. S., Lin, Y., Kong, Z. H., Zhang, Y., Zheng, B. D., \& Zeng, S. X. (2018). Photodynamic inactivation of Burkholderia cepacia by curcumin in combination with EDTA. Food Research International, 111, 265-271.

24. Spurr, A. R. (1969). A low-viscosity epoxy resin embedding medium for electron microscopy. Journal of Ultrastructure Research, 26(1), 31-43.

25. Huang, J. M., Chen, B. W., Li, H. H., Zeng, Q. H., Wang, J. J., Liu, H. Q., Pan, Y. J., \& Zhao, Y. (2020). Enhanced antibacterial and antibiofilm functions of the curcumin-mediated photodynamic 
inactivation against Listeria monocytogenes. Food Control, 108, 8.

26. Lippman, B., Yao, S. Y., Huang, R. Z., \& Chen, H. Q. (2020). Evaluation of the combined treatment of ultraviolet light and peracetic acid as an alternative to chlorine washing for lettuce decontamination. International Journal of Food Microbiology, $323,9$.

27. Berney, M., Weilenmann, H.-U., \& Egli, T. (2006). Flow-cytometric study of vital cellular functions in Escherichia coli during solar disinfection (SODIS). Microbiology, 152, 1719-1729.

28. Dai, T., Huang, Y. Y., \& Hamblin, M. R. (2009). Photodynamic therapy for localized infections-State of the art. Photodiagnosis and Photodynamic Therapy, 6(3-4), 170-188.

29. Li, T., Zhao, Y., Matthews, K., Gao, J., Hao, J., Wang, S., Han, J., \& Jia, Y. (2020). Antibacterial activity against Staphylococcus aureus of curcumin-loaded chitosan spray coupled with photodynamic treatment. LWT-Food Science and Technology, 134, 110073.

30. Ghate, V. S., Ng, K. S., Zhou, W., Yang, H., Khoo, G. H., Yoon, W.-B., \& Yuk, H.-G. (2013). Antibacterial effect of light emitting diodes of visible wavelengths on selected foodborne pathogens at different illumination temperatures. International Journal of Food Microbiology, 166(3), 399-406.

31. Vinayak, S. G., Weibiao, Z., \& Hyun-Gyun, Y. (2019). Perspectives and trends in the application of photodynamic inactivation for microbiological food safety. Comprehensive Reviews in Food Science and Food Safety, 18(2), 402-424.

32. Song, L., Farrah, S. R., \& Baney, R. H. (2011). Bacterial inactivation kinetics of dialdehyde starch aqueous suspension. Polymers, 3(4), 1902-1910.

33. Kumar, A., Ghate, V., Kim, M. J., Zhou, W. B., Khoo, G. H., \& Yuk, H. G. (2017). Inactivation and changes in metabolic profile of selected foodborne bacteria by $460 \mathrm{~nm}$ LED illumination. Food Microbiology, 63, 12-21.

34. Vinayak, G., Ai Ling, L., Amit, K., Woo Suk, B., Weibiao, Z., \& Hyun-Gyun, Y. (2015). Enhancing the antibacterial effect of 461 and $521 \mathrm{~nm}$ light emitting diodes on selected foodborne pathogens in trypticase soy broth by acidic and alkaline $\mathrm{pH}$ conditions. Food Microbiology, 48, 49-57.

35. Kim, M. J., Ng, B. X. A., Zwe, Y. H., \& Yuk, H. G. (2017). Photodynamic inactivation of Salmonella enterica Enteritidis by 405 +/-5-nm light-emitting diode and its application to control salmonellosis on cooked chicken. Food Control, 82, 305-315.

36. $\mathrm{Hu}$, X. Q., Huang, Y. Y., Wang, Y. G., Wang, X. Y., \& Hamblin, M. R. (2018). Antimicrobial photodynamic therapy to control clinically relevant biofilm infections. Frontiers in Microbiology, 9, 24.

37. Bertoloni, G., Lauro, F. M., Cortella, G., \& Merchat, M. (2000). Photosensitizing activity of hematoporphyrin on Staphylococcus aureus cells. Biochimica et Biophysica Acta (BBA)-General Subjects, 1475(2), 169-174.

38. Deng, X., Tang, S., Wu, Q., Tian, J., Riley, W. W., \& Chen, Z. (2016). Inactivation of Vibrio parahaemolyticus by antimicrobial photodynamic technology using methylene blue. Journal of the Science of Food and Agriculture, 96(5), 1601-1608.

39. Penha, C. B., Bonin, E., Silva, AFd., Hioka, N., Zanqueta, E. B., Nakamura, T. U., Filho, BAd. A., Campanerut-Sa, P. A. Z., \& Mikcha, J. M. G. (2017). Photodynamic inactivation of foodborne and food spoilage bacteria by curcumin. LWT-Food Science and Technology, 76(Part B), 198-202.

40. Ghate, V. S., Zhou, W. B., \& Yuk, H. G. (2019). Perspectives and trends in the application of photodynamic inactivation for microbiological food safety. Comprehensive Reviews in Food Science and Food Safety, 18(2), 402-424.

41. Lin, Y. L., Hu, J. M., Li, S. Y., Hamzah, S. S., Jiang, H. Q., Zhou, A. R., Zeng, S. X., \& Lin, S. L. (2019). Curcumin-based photodynamic sterilization for preservation of fresh-cut Hami melon. Molecules, 24(13), 10.

42. Jahid, I. K., Han, N. R., Srey, S., \& Ha, S.-D. (2014). Competitive interactions inside mixed-culture biofilms of Salmonella Typhimurium and cultivable indigenous microorganisms on lettuce enhance microbial resistance of their sessile cells to ultraviolet $\mathrm{C}$ (UV-C) irradiation. Food Research International, 55, 445-454.

43. Ukuku, D. O., \& Fett, W. F. (2002). Relationship of cell surface charge and hydrophobicity to strength of attachment of bacteria to cantaloupe rind. Journal of Food Protection, 65(7), 1093-1099.

44. Monier, J. M., \& Lindow, S. E. (2005). Aggregates of resident bacteria facilitate survival of immigrant bacteria on leaf surfaces. Microbial Ecology, 49(3), 343-352.

45. Tortik, N., Spaeth, A., \& Plaetzer, K. (2014). Photodynamic decontamination of foodstuff from Staphylococcus aureus based on novel formulations of curcumin. Photochemical \& Photobiological Sciences, 13(10), 1402-1409.

46. Pace, B., Capotorto, I., Palumbo, M., Pelosi, S., \& Cefola, M. (2020). Combined effect of dipping in oxalic or in citric acid and low $\mathrm{O}(2)$ modified atmosphere, to preserve the quality of fresh-cut lettuce during storage. Foods, 9(8), 988.

47. Wills, R. B. H., Pristijono, P., \& Golding, J. B. (2008). Browning on the surface of cut lettuce slices inhibited by short term exposure to nitric oxide (NO). Food Chemistry, 107(4), 1387-1392.

48. Perombelon, M. C. M. (2002). Potato diseases caused by soft rot erwinias: an overview of pathogenesis. Plant Pathology, 51(1), $1-12$.

49. Tao, T., Ding, C., Han, N., Cui, Y., Zhang, C. J. F. P., \& Life, S. (2019). Evaluation of pulsed light for inactivation of foodborne pathogens on fresh-cut lettuce: Effects on quality attributes during storage. Food Packaging and Shelf Life, 21, 100358. 